\title{
The Management of Humidifying Treatment for Low Contamination Risks During Indoor Cultivation of Grey Oyster Mushroom (Pleurotus pulmonarius)
}

\author{
Md. Tariqul Islam ${ }^{1, *}$, Zarina Zakaria ${ }^{2}$, Nasrul Hamidin ${ }^{3}$, Mohd Azlan Bin Mohd Ishak ${ }^{4}$, \\ and Chong Shi Fern \\ ${ }^{1}$ School of Bioprocess Engineering, Universiti Malaysia Perlis (UniMAP), 02600 Arau, Perlis, \\ Malaysia. \\ ${ }^{2,5}$ Faculty of Engineering Technology, Universiti Malaysia Perlis (UniMAP), 02100 Padang Besar, \\ Perlis, Malaysia. \\ ${ }^{3}$ School of Environmental Engineering, Universiti Malaysia Perlis (UniMAP), 02600 Arau, Perlis, \\ Malaysia. \\ ${ }^{4}$ Universiti Technology MARA (UiTM), Perlis Campus, 02600 Arau, Perlis, Malaysia.
}

\begin{abstract}
In this study, grey oyster mushroom (Pleurotus pulmonarius) was cultivated in indoor controlled environment to seeking out the possible risks of contamination and ways of treatment to avoid the contamination. For this, mushroom was cultivated in providing artificial humidifying and ventilation system to ensure optimum humidity (80-90\%) and fresh air recirculation in different ways of treatment. The ways of treatment were included as in position of humidifier, frequency of humidifying, plastic cork of bags opening part and cleaning of humidifier water container. Maximum percentages of bag contamination (2.5-25.30\%), cap contamination (5.6-30.75\%), stalk contamination $(4.75-23.25 \%)$ and root contamination (2.6-18.45\%) were found in front to front humidifier position, long humidifying with long interval frequency, without plastic cork, without cleaning and bi-monthly cleaning of humidifier water container treatment but no diseases and pest infection was found. Whereas, very low percentages of contamination $(0.1-0.5 \%)$ were found in surrounding humidifying position, short humidifying duration with short interval frequency, with plastic cork and weekly cleaning of humidifier water container treatment.
\end{abstract}

\section{Introduction}

Mushrooms of Pleurotus spp. are commonly known as oyster mushrooms which occupy the second position among most cultivated edible mushrooms worldwide due to their nutritional and medicinal values [1-3]. Pleurotus spp. were able to produce a maximum

\footnotetext{
* Corresponding author: zarinaz@unimap.edu.my
} 
yield when cultivated on sterilized sawdust substrate in a control environment [4]. The mushroom requires low temperature and high relative humidity to produce fruiting bodies $[5,6]$, whereas, high temperatures caused deformed fruiting body and consequencely low mushroom yield [6]. Kong (2004) reported that P. ostreatus, P. florida, P. sajor-caju can reach their optimum growth at temperature of $25-30^{\circ} \mathrm{C}$ [7]. Chang (2008) reported a humidity at $80-95 \%$ was optimum for formation of fruiting bodies and at relative humidity lower than $80 \%$, the fruiting bodies may dry out easily [8]. Jang et al. (2003) suggested that, $80 \%$ or more relative humidity is suitable for the formation of highest cap size and individual weight of the P. ostreatus and the cap size and stipe thickness started to decrease at lower than $80 \%$ and decreased severely at $60 \%$ or less relative humidity [9]. Yang et al. (2013) reported that, during the fruiting period, the suitable air relative humidity can be as high as $85-90 \%$ [10].

High humidity in mushroom cultivation surrounding in the other way can cause disease from the microbial contamination [11]. Upadhyay et al. (2011) reported that humidity should be kept low (60-70\%) to prevent microbial contamination when the protecting plastic sheets are removed $[13,14]$. Contamination in mushroom cultivation always require the growers to establish new facilities to stop the spreading out of contaminants and therefore increase the production cost $[15,16]$. So, from above all literature it is clear that high humidity is the most essential factor for mushroom cultivation and for indoor cultivation an artificial humidifying system is needed to achieve the favourable humidity. Since then, there is no study yet on the possible risks of contamination for mushrooms under controlled humidifying condition and their managements to avoid such situation. Therefore this study had conducted to investigate the possible risks of contamination and their management during indoor cultivation of Pleurotus pulmonarius which helps to avoid the contamination that can ensure proper quality and yield of mushrooms.

\section{Materials and methods}

\subsection{Preparation of mushroom growing bags}

Substrate's for preparing mushroom bags were prepared by established mushroom cultivators. The substrates were formulated by the mixture of saw dust, rice bran and agricultural lime with the ratio of 100:10:1. The mixtures were packed in autoclavable polypropylene bags $(6 \times 9 \mathrm{inch})$ and sterilized at 20 psi pressure and $121^{\circ} \mathrm{C}$ temperatures for 6 hours to remove spore of bacteria, fungi and other microorganisms [16]. After sterilization, it was cooled at room temperature and injected with spawn prepared through tissue culture technique. Then the opening parts of the bags were closed by plastic cork, paper and rubber band to protect loss of moisture content from inside the bags and left it vertically for 30-35 days in dark for mycelium colonization. The mycelium colonization was completed when the bags were fully covered by white colour mycelium. Then the bags with completed colonization were transferred into a growing room inside a building. Cultivation period was counted from the first day of bags were transferred and arranged in the cultivation room.

\subsection{Design of indoor cultivation room}

The indoor cultivation room was measured at $5.8 \mathrm{~L} \times 4.57 \mathrm{~W} \times 2.74 \mathrm{H} \mathrm{m}^{3}$ in size. The wall was made by bricks at one side and gypsum board on the rest of the walls. The room was installed with four rows of racks; each rack contained four iron bars distance by $15 \mathrm{~cm}$ 
from each other and $55 \mathrm{~cm}$ distance between the racks. The room was also installed with roof ventilation system and light in order to facilitate fresh air and maintain proper light intensity respectively. The bags were placed horizontally through the racks by using rope and made it tight by cable tie and hanged vertically. Twelve bags were arranged in one column of rope by 3 bags in together in 4 parts. A total of 100 columns of rope were used to arrange 1200 bags. The columns of rope were arranged at $25 \mathrm{~cm}$ distance from each other in every rack. The distance of the top end bag from the ceiling was $76 \mathrm{~cm}$ and the down end bag from the floor was $30 \mathrm{~cm}$.

\subsection{Position of humidifier}

After complete colonization the bags were transferred into the growing room and arranged as mentioned above. The humidifiers were placed inside the growing room at two positions, 'Faced to Faced' and 'Surrounding'. In 'Faced to Faced', the humidifier was placed between the two columns of bags where the distance from the column to humidifier was $15 \mathrm{~cm}$ in both side and the opening parts (mouth to come out fruitbody) of the bags were faced to the humidifier. In the 'Surrounding', the humidifier was placed also between the two columns of bags but the distance between the opening part of the bags (front view) and humidifier were $25-30 \mathrm{~cm}$, between side view to humidifier were $20-25 \mathrm{~cm}$ and back view to humidifier $10-15 \mathrm{~cm}$ (Fig. 1a). In both positions, the humidity was maintained at $80-90 \%$ using the humidifiers. The data was collected on the basis of percentages of bags, stalk, cap and root contamination.

\subsection{Humidifying frequency}

Two ways of humidifying frequency was conducted; a long humidifying with long interval (LHLI) and short humidifying with short interval (SHSI). In LHLI, two units of humidifier were placed at 3.5-4 m distance from each other and it was applied 30 minutes with 45 minutes interval from two positions to maintain $80-90 \%$ indoor humidity. Whereas in SHSI, four units of humidifiers were placed at 2-2.5 m distance from each other's and it was applied 15 minutes with 15 minutes interval from four positions to maintain $80-90 \%$ indoor humidity. The humidifiers in both treatments were configured as followed by timer:

$$
\begin{aligned}
& \text { LHLI:- } 30 \mathrm{H} 1+45 \mathrm{I}+30 \mathrm{H} 2+45 \mathrm{I}+30 \mathrm{H} 1+45 \mathrm{I}+30 \mathrm{H} 2+45 \mathrm{I}+\ldots \ldots \ldots \ldots \ldots \ldots \ldots \\
& \text { SHSI:- } 15 \mathrm{H} 1+15 \mathrm{I}+15 \mathrm{H} 2+15 \mathrm{I}+15 \mathrm{H} 3+15 \mathrm{I}+15 \mathrm{H} 4+15 \mathrm{I}+15 \mathrm{H} 1+15 \mathrm{I}+15 \mathrm{H} 2+15 \mathrm{I}+15 \mathrm{H} 3+\ldots . . \\
& { }^{*} \mathrm{H} 1, \mathrm{H} 2, \mathrm{H} 3, \mathrm{H} 4 \text { = Humidifier; 1,2,3,4. I= Interval }
\end{aligned}
$$

Mushroom was cultivated in this both humidifying system with continuous ventilation. The data was collected on the basis of percentages of bags, stalk, cap and root contamination.

\subsection{Plastic cork of bags opening part}

In this method the bags were cultivated with and without the plastic cork that was used in the opening part during substrate packing. After arranging the completed colonization bags in the growing room, $50 \%$ plastic cork were removed and another $50 \%$ were not removed (Fig. 1b). Thus all the bags were cultivated in same environment by providing artificial 
humidifying and ventilation to maintain $80-90 \%$ humidity and proper air circulation. The data was collected on the basis of percentages of bags, stalk, cap and root contamination.

a

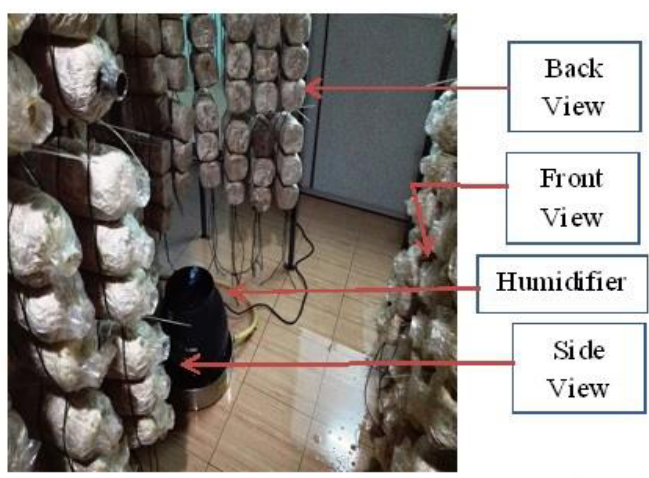

b

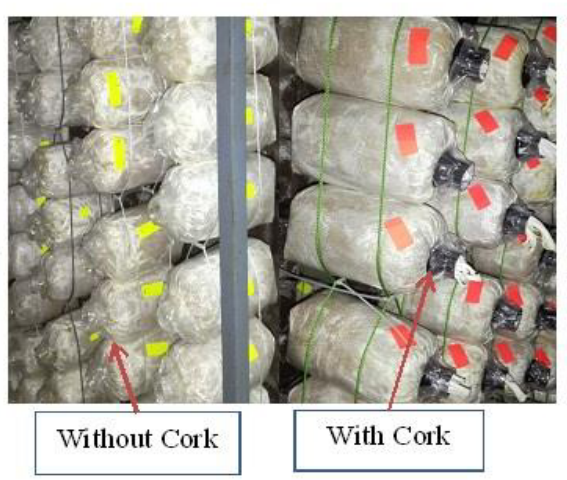

c

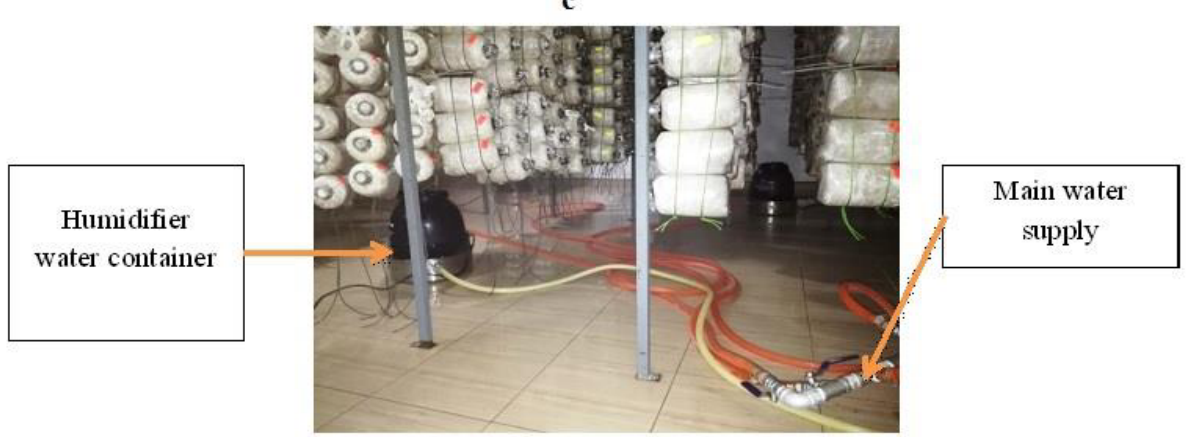

Fig. 1. Different ways of management for indoor mushroom cultivation (a: Position of humidifier; $b$ : Plastic cork; c: Humidifier water container)

\subsection{Cleaning of water container}

The water container which contained water sources for humidifying was subjected to three ways of cleaning treatment (Fig. 1c). First treatment was the control, where no cleaning was conducted throughout the cultivation period. The second treatment was bi-monthly cleaning and the third was weekly cleaning. The data was collected on the basis of percentages of bags, stalk, cap and root contamination.

\subsection{Data collection and analysis}

The percentages of different contamination including bags, caps, stalk and root was calculated as follows:

$$
\text { Contamination }(\%)=\frac{\text { Total }(\text { Bag or cap or stalk or root }) \text { Contaminated }}{\text { Total numbers of bag or cap or stalk or root }} \times 100 \text {. (1) }
$$

The collected data were analyzed as descriptive statistic and one way ANOVA test where the significant level was considered lower than 0.05 at p-value. All of the statistical calculations were executed using SPSS 10.0. 


\section{Results and discussion}

The highest percentage of contaminated bags was recorded as $25.30 \%, 20.33 \%, 15.5 \%$, $5.6 \%$ and $2.5 \%$ in LHLI, front to front, without cork, without cleaning and bi-monthly cleaning applications respectively. On the other hand, the lowest was found as $0.25 \%, 0.4 \%$ and $0.5 \%$ in SHSI, with cork, weekly cleaning and surrounding humidifying treatments (Table 1; Fig. 2).

Table 1. Percentages of contaminations in different ways of treatment during indoor mushroom cultivation.

\begin{tabular}{|c|c|c|c|c|c|}
\hline & & \multicolumn{4}{|c|}{ Types of Contamination } \\
\hline Methods & Treatments & $\operatorname{Bag}(\%)^{1}$ & Stalk $(\%)^{2,4}$ & Cap (\%) ${ }^{2,3,6}$ & $\operatorname{Root}(\%)^{5}$ \\
\hline \multirow{2}{*}{$\begin{array}{l}\text { Position } \\
\text { of humidifier }\end{array}$} & Front to Front & $20.33 \pm 1.1$ & $10.45 \pm 1.6$ & $25.65 \pm 2.5$ & $15.75 \pm 1.9$ \\
\hline & Surrounding & $0.50 \pm .2$ & $0.50 \pm .2$ & $0.25 \pm .05$ & $0.25 \pm .1$ \\
\hline \multirow{2}{*}{$\begin{array}{l}\text { Humidifying } \\
\text { Frequency }\end{array}$} & LHLI & $25.30 \pm 1.9$ & $20.56 \pm 2.4$ & $30.75 \pm 3.2$ & $18.45 \pm 2.9$ \\
\hline & SHSI & $0.25 \pm .13$ & $0.20 \pm .1$ & $0.23 \pm .2$ & $0.23 \pm .1$ \\
\hline \multirow{2}{*}{$\begin{array}{lr}\text { Plastic } & \text { Cork of } \\
\text { Bags } & \text { Opening } \\
\text { Part } & \end{array}$} & Without Cork & $15.50 \pm 1.9$ & $4.75 \pm 2.4$ & $5.60 \pm 2.1$ & $13.45 \pm 1.8$ \\
\hline & With Cork & $0.40 \pm .3$ & $0.20 \pm .1$ & $0.32 \pm .1$ & $0.33 \pm .1$ \\
\hline \multirow{3}{*}{$\begin{array}{l}\text { Cleaning } \\
\text { of } \\
\text { Container }\end{array}$} & Without & $5.60 \pm 1.9$ & $23.25 \pm 2.7^{4}$ & $30.40 \pm 2.0^{6}$ & $7.56 \pm 2.8$ \\
\hline & Bi-monthly & $2.50 \pm 1.2$ & $7.20 \pm 1.9^{4}$ & $10.70 \pm 2.9^{6}$ & $2.40 \pm .6$ \\
\hline & Weekly & $0.40 \pm .2$ & $0.25 \pm .1$ & $0.50 \pm .2$ & $0.22 \pm .1$ \\
\hline
\end{tabular}

The highest percentages of contaminated stalk was found as $23.25 \%, 20.56 \%, 10.45 \%$, $7.2 \%$ and $4.75 \%$ in without cleaning, LHLI, front to front, bi-monthly cleaning and without cork application, whereas the lowest were $0.2 \%, 0.25 \%$ and $0.5 \%$ as found in with cork, SHSI, weekly re-cleaning and surrounding humidifying treatments respectively (Table 1; Fig. 2). The highest contaminated cap of $30.75 \%, 30.4 \%, 25.65 \%, 10.7 \%$ and $5.6 \%$ was found in LHSI, without cleaning, front to front, bi-monthly cleaning and without cork treatment respectively. On the other hand, the lowest of $0.1 \%, 0.25 \%$ and $0.5 \%$ was found in SHSI, surrounding humidifying, with cork and weekly cleaning treatment respectively. Finally, the highest contaminated root of $18.45 \%, 15.75 \%, 13.45 \%, 7.56 \%$ and $2.4 \%$ was found in LHLI, front to front, without plastic cork, without cleaning and bi-monthly cleaning treatment respectively. Instead, the lowest of $0.1 \%, 0.25 \%$ and $0.33 \%$ was found in SHSI, weekly cleaning, surrounding humidifying and with cork application respectively (Table 1; Fig. 2). All the types of contamination in different ways of treatment for indoor cultivation were found statistically significant in one-way ANOVA test at .000 significant value. 
1

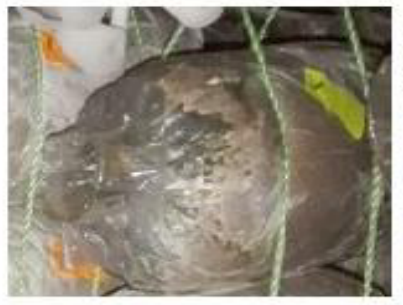

4

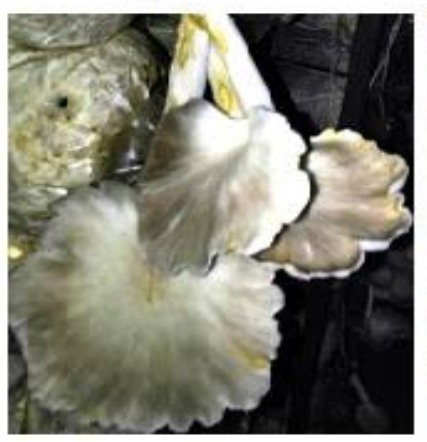

2

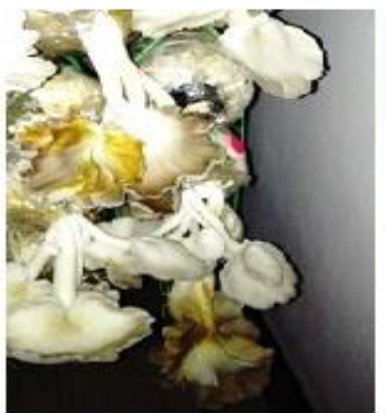

5

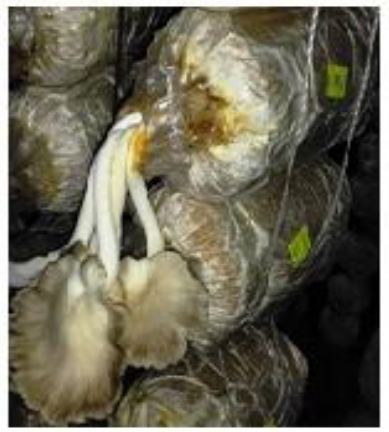

3

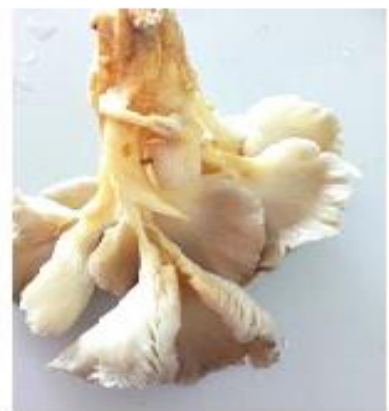

6

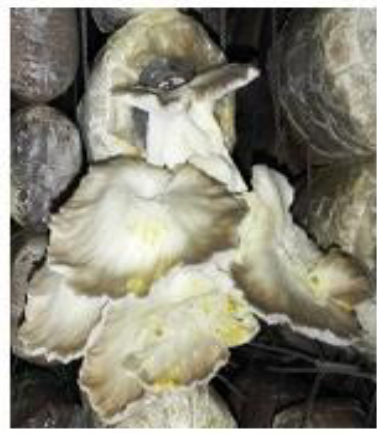

Fig. 2. Contaminated bags (1), caps $(2,3,6)$, stalk $(2,4)$ and root $(5)$ in different ways of treatment for indoor cultivation.

The results showed that the humidifying in front of the bags opening part with short distance, LHSI, without plastic cork, without and bi-monthly cleaning of humidifier water container application were applications identified to impose high risk for contamination. Those applications provided easy access of contaminated vapour into the bags and fruting bodies. Moreover, contamination was also found in without and bi-monthly cleaning application because in both applications the water container became dirty and produced bad smells which indication of water contamination. The contaminated water was sprayed as vapor by humidifier and consequently contaminated the bags and fruitbodies. Deacon, (2013) reported that, excessive water can cause disease, contamination and poor mushroom quality [11]. In this present study, no disease was found but contaminated bags and fruiting bodies were found in different ways of application.

On the other hand, surrounding humidifying, short humidifying with short distance, with plastic cork of the bags mouth and weekly cleaning were found had caused low risks of contamination. Surrounding humidifying provided a proper distance between bags and humidifier so as not excessive vapour had penetrated directly into the bags opening and into the fruitbodies. Other treatments such as the plastic cork, weekly cleaning of water container also ensured fresh water and vapour surrounding the cultivation room. Therefore this study suggested that management of humidifying conditions may reduce certain percentage of water-caused contamination and to ensure the present of water will give positive effect and not vice versa. 


\section{Conclusion}

This study found that humidifying application could be imposed contamination for certain percentages of bags and fruitbodies. Therefore, the management of humidifying conditions as suggested in this study may reduce the risks of disease from water-caused contamination.

\section{References}

1. M.A. Khan, M. Tania, S.M.R. Amin, N. Alam, M.N. Uddin, Bangladesh J. Mushroom, 2, 17 (2008).

2. S.A. Ahmed, J.A. Kadam, V.P. Mane, S.S. Patil, M.M.V. Baig, Nat. Sci., 7, 44 ( 2009).

3. U. Lindequist, T.H J. Niedermeyer, W.D. Julich, Evidence-Based Complement. Altern. Med., 2, 285 (2005).

4. E.S. Dias, Ciencia e Agrotecnologia, 34, 795 (2010).

5. P. Patel, R. Trivedi, Int. J. Sci. Res., 4, 1126 ( 2015).

6. N. Klomklung, S.C. Karunarathna, K.D. Hyde, E. Chukeatirote, Acta Biol. Szegedlensis, 58, 39 (2014).

7. W.S. Kong, Oyster mushroom Cultiv. Part II. Oyster mushrooms. Seoul Heineart Inc., 54 (2004).

8. S.T. Chang, Mushrooms as Funct. foods, 1 (2008).

9. K.Y. Jang, C.S. Jhune, J.S. Park, S.M. Cho, H.Y. Weon, J.C. Cheong, S.G. Choi, J.M. Sung, Mycobiology, 31, 145 ( 2003).

10. J. Yang, J. Zhao, H. Yu, Y. Wang, R. Wang, L. Tang, Computer and Computing Technologies in Agriculture VI, (Springer, China, 2013).

11. J. Deacon, Fungal Biology, (John Wiley \& Sons, UK, 2013).

12. R.C. Upadhyay, M. Singh, Industrial Applications, (Springer, Germany, 2011).

13. A.W. Chen, Mushroom Grower's Handbook1, ( Springer, Netherlands, 2004).

14. T. Hyunjong Kwon, Mushroom Grower's Handbook 1, (Mush World, China, 2004).

15. S.W. Kang, Mushroom Grower's Handbook 1, (MushWorld, China, 2004).

16. J. Christopher, D. Custodio, Mushroom Grower's Handbook 1, (MushWorld, China, (2004). 